\title{
Editorial
}

\section{Cuidar em liberdade e promover a cidadania}

\author{
Elisabete Ferreira Mângia \\ Fernanda Nicácio
}

\begin{abstract}
De 28 de junho a 01 de julho de 2004 foi realizado, em São Paulo, o Congresso Brasileiro de Centros de Atenção Psicossocial (CAPS), promovido pelo Ministério da Saúde com apoio da Secretaria de Saúde do Município. Reafirmando as diretrizes da política nacional de saúde mental no contexto do Sistema Único de Saúde (SUS), o evento intitulado "Saúde Mental. Cuidar em liberdade e promover a cidadania" reuniu mais de 2000 pessoas, entre trabalhadores e coordenadores de CAPS, representantes de associações de usuários e familiares, coordenadores municipais e estaduais de saúde mental, gestores do SUS, docentes e pesquisadores de todos os Estados da federação.

São múltiplos os desafios colocados para a realização de um evento desse porte, que buscou priorizar a efetiva participação de todos os 534 serviços de atenção psicossocial então existentes: 186 CAPS I, 222 CAPS II, 24 CAPS III, 63 CAPS ad e 39 CAPSi (BRASIL, 2004a). Nas reuniões preparatórias do Congresso, a Comissão Organizadora e de Programação colocaram a indagação: como produzir um congresso que possibilite a reflexão sobre as múltiplas experiências dos CAPS, seu fortalecimento e a implementação de novas práticas? A interrogação, apenas aparentemente simples, não encontrava respostas fáceis e requeria a produção de debate e de construção coletiva. Processualmente, as diretrizes da reforma psiquiátrica, a singularidade das experiências locais, a narrativa das práticas, a multiplicidade de atores e a diversidade de perspectivas afirmaram-se para compor a programação do evento.

Assim, o Congresso foi organizado a partir de três eixos temáticos discutidos em três mesas-redondas e dezoito grupos de trabalho. O primeiro eixo, "CAPS, laços sociais" visava refletir sobre a inscrição dos CAPS nas políticas públicas de saúde e intersetoriais, a potencialização e articulação das redes territoriais e, sobretudo, o lugar estratégico dos CAPS na efetiva substituição do modelo asilar e na tessitura de laços sociais, inventando interfaces e conexões que possibilitem novas cartografias para a experiência da loucura. O segundo eixo, "Cuidado Cotidiano nos CAPS", tematizou as experiências de produção de uma nova prática terapêutica e de transformação da cultura na relação com as pessoas com a experiência do sofrimento psíquico. Desafios, tensões e possibilidades que são descobertos no dia-a-dia na produção do cuidar em liberdade, de portas abertas que, buscando superar os modos de pensar reducionistas e as diferentes formas invalidantes de tutela, possibilite o encontro com o outro, o diálogo com sua história, desejos e projetos, o cuidar do sofrimento, a interação em suas redes relacionais; "estar-com", tecer relações e, em conjunto, inventar percursos e projetos propiciadores de autonomia, de ampliação de poder contratual e de novas redes de trocas e de possibilidades de vida nos territórios. "Saber cuidar", na instigante síntese de Leonardo Boff.
\end{abstract}


“Trabalhadores, usuários e familiares: transformando relações e produzindo novos diálogos" foi o tema do terceiro eixo. Tratava-se de discutir as práticas cotidianas que, assumindo os desafios de produção de novas profissionalidades, parcerias e protagonismo de todos os atores, possam transformar as relações entre as pessoas e as instituições, promover tecidos sociais solidários, validar saberes e recursos, agenciar projetos pautados na economia solidária e co-produzir emancipação e garantia, acesso e exercício de direitos, bases e horizonte da reforma psiquiátrica.

A partir desses três eixos norteadores, plenárias de socialização dos grupos de trabalho, oficinas, cursos, conferências, apresentações artísticas e pontos de encontro integravam a extensa programação do Congresso. Destacaram-se, também, a "Mostra Nacional de Produtos e Idéias dos CAPS" e a Mostra "No Centro da Vida" de exposição de obras de arte nas modalidades de pintura, escultura e desenho (BRASIL, 2004b).

Discutir e compartilhar a singularidade das experiências inscritas em diversos contextos locais, expor conflitos, descobrir caminhos diferentes para refletir sobre as múltiplas indagações vivenciadas no cotidiano das instituições, conhecer novos itinerários para habitar os territórios, andar, conversar e pensar nos espaços do congresso, com a inspiração de David Capistrano, Foucault, Basaglia, Guattari, Artaud, Nise da Silveira, Arthur Bispo do Rosário e tantos artistas e artesãos, autores-guia que nomeavam as salas do evento, criaram um clima instigante que mesclava passado e presente, o quanto tem sido feito e o muito a fazer, intensidade e polifonia de idéias, mensagens diversas que desenhavam a possibilidade de produção democrática de políticas públicas de afirmação de direitos e de projetos coletivos tecidos na diversidade.

Em síntese, a realização do Congresso Brasileiro de CAPS e os ecos produzidos em tantos lugares reafirmam a utopia "Por uma sociedade sem manicômios", exigência do presente.

\section{REFERÊNCIAS}

BRASIL. MINISTÉRIO DA SAÚDE. Planilha dados CAPS. Brasília, junho 2004a.

BRASIL. MINISTÉRIO DA SAÚDE. Saúde mental: cuidar em liberdade, promover a cidadania. Caderno Informativo do Congresso Brasileiro de Centros de Atenção Psicossocial. Brasília, 2004b. 